\title{
BMJ Open Family physicians supporting patients with palliative care needs within the patient medical home in the community: an appreciative inquiry study
}

\author{
Amy Tan (D) , ${ }^{1,2}$ Ronald Spice, ${ }^{2,3}$ Aynharan Sinnarajah (1) ${ }^{3}$
}

To cite: Tan A, Spice R, Sinnarajah A. Family physicians supporting patients with palliative care needs within the patient medical home in the community: an appreciative inquiry study. BMJ Open 2021;11:e048667. doi:10.1136/ bmjopen-2021-048667

- Prepublication history and additional supplemental material for this paper are available online. To view these files, please visit the journal online (http://dx.doi.org/10.1136/ bmjopen-2021-048667)

Received 04 January 2021 Accepted 08 November 2021

\section{A) Check for updates}

(c) Author(s) (or their employer(s)) 2021. Re-use permitted under CC BY-NC. No commercial re-use. See rights and permissions. Published by BMJ.

${ }^{1}$ Palliative Care, The University of British Columbia, Victoria, British Columbia, Canada

${ }^{2}$ Family Medicine, University of Calgary Cumming School of Medicine, Calgary, Alberta, Canada

${ }^{3}$ Palliative Care, University of Calgary Cumming School of Medicine, Calgary, Alberta, Canada

Correspondence to

Dr Amy Tan;

amy.tan1@ucalgary.ca

\section{ABSTRACT}

Objectives Canadians want to live and die in their home communities. Unfortunately, Canada has the highest proportion of deaths in acute care facilities as compared with other developed nations. This study aims to identify the essential components required to best support patients and families with palliative care needs in their communities to inform system changes and empower family physicians (FPs) in providing community-based palliative care for patients.

Design Appreciative inquiry (Al) methodology with individual interviews. Interview transcripts were analysed iteratively for emerging themes and used to develop 'possibility statements' to frame discussion in subsequent focus groups. A conceptual framework emerged to describe the 'destiny' state as per Al methods.

Setting FPs, palliative home care providers, patients and bereaved caregivers were recruited in the urban and surrounding rural health authority zones of Calgary, $A B$, Canada.

Participants 9 females and 9 males FPs (range of practice years 2-42) in interviews; 8 bereaved caregivers, 1 patient, 26 palliative home care team members in focus groups. Interviews and focus groups were recorded digitally and transcribed with consent.

Results The identified themes that transcended all three groups created the foundation for the conceptual framework. Enhanced communication and fostering team relationships between all care providers with the focus on the patient and caregivers was the cornerstone concept. The FP/patient relationship must be protected and encouraged by all care providers, while more system flexibility is needed to respond more effectively to patients. These concepts must exist in the context that patients and caregivers need more education regarding the benefits of palliative care, while increasing public discourse about mortality.

Conclusions Key areas were identified for how the patient's team can work together effectively to improve the patient and caregiver palliative care journey in the community with the cornerstone element of building on the trusting FP-patient longitudinal relationship.

\section{BACKGROUND}

Canadians want to live and die in their communities $^{1}$ as they are growing older and living

\section{Strengths and limitations of this study}

- This study uses appreciative inquiry qualitative methods to identify the essential components required to best support patients and families with palliative care needs in their communities.

- Multiple perspectives recruited including: community-based family physicians (FPs), palliative home care clinicians, patients and bereaved caregivers.

- Analysis was focused on the FPs' interviews to derive 'possibility statements' and used to frame the focus groups with the other groups of participants.

- Generalisability may be limited due to the lack of diversity in participants recruited for the patients and bereaved caregivers in terms of ethnicity, age and gender.

- Patients and caregivers may have been reluctant to volunteer for this study as it involved discussing palliative care.

longer with chronic conditions and multimorbidity. Unfortunately, Canada has the highest proportion of deaths in acute care facilities (62\%) and higher mean per capita hospital expenditures as compared with other developed nations ${ }^{2}{ }^{3}$ There is a discrepancy between where Canadians want to die, and where they actually die. Although communitybased primary palliative care (CPPC) is a core competency for Canadian family physicians (FPs), ${ }^{4}$ a decreasing number of practising FPs self-identify as providing CPPC to their patients, leading to declining availability of FPs to care for housebound patients with palliative care needs. Three out of five primary care physicians in Canada report that they are unprepared to meet the palliative care needs of their patients. ${ }^{1}$ There is also an erosion of palliative care within primary care in other developed nations in the world, including the UK, the Netherlands and Australia. ${ }^{5-7}$

Palliative care is defined by the $\mathrm{WHO}$ as an approach to care that improves the quality 
of life of people with serious or life-limiting diseases, provides support to their families, and focuses on the assessment and management of physical symptoms and psychosocial and spiritual concerns. ${ }^{8}$ Primary palliative care is defined as palliative care provided by clinicians who are not specialty palliative care clinicians, including primary care physicians and oncologists, that is integrated into the care of patients in a patient-centred approach. ${ }^{69}$ Given that FPs in Canada practice holistic patient-centred care where their patients live, a purposeful integration of CPPC within family medicine in Canada is both appropriate and essential for high quality and efficient primary care.

It is not known why there is a discrepancy between the increasing need for Canadian FPs to support their patients with palliative care needs, and the decreasing engagement or willingness (as perceived by patients and palliative care consultants) of FPs to provide such care. Consequently, it is unclear as to how FPs can be better supported in their practices to provide for the care of palliative patients in their communities.

To understand the impact of low community-based FP involvement in palliative care, one must determine what is required to better prepare and empower FPs for the increasing palliative care needs of an ageing population with multimorbidity. ${ }^{6}$ Improved FP involvement would also allow patients to benefit from an earlier palliative approach and more effective chronic disease management. $^{610}$

This study aimed to explore and describe the current landscape of FPs' involvement in providing CPPC to patients within the patient medical home $(\mathrm{PMH})^{11}$ in a metropolitan city and surrounding rural communities in Southern Alberta, Canada. The PMH is the model of primary care that Canadian healthcare systems are striving for, which will involve readily accessible primary care for each registered patient, 'centred on the patients' needs, provided throughout every stage of life (which should thus include palliative care), and seamlessly integrated with other services in the healthcare system and the community'. ${ }^{11}$ We have included the perspectives of palliative home care (PHC) providers who are key partners of FPs in the delivery of community-based palliative care. Further, we have explored the perspectives of the recipients of the care: patients with palliative care needs and their unpaid caregivers. These perspectives were explored to identify the essential components required to best support patients and families with palliative care needs in their communities throughout their illness trajectories to inform system changes and empower FPs in providing CPPC for patients.

\section{METHODS}

A qualitative method with an appreciative inquiry (AI) approach was used for this study. The design, data collection and analysis align with the Standards for Reporting Qualitative Research ${ }^{12}$ The AI approach encourages a strengths-based, forward-looking approach that focuses on positive changes and solutions to maintain and build on successes encountered by clinicians who are supporting patients and their families with communitybased palliative care needs. ${ }^{13-16}$ Participants were asked to 'discover', 'dream' and 'design' ${ }^{13}$ their ideal environment to best support their patients with palliative care needs, and discuss their role and needs with this environment. Patients and caregivers were asked to determine what they would need to better support their loved ones if they were to advise others to achieve a better palliative care experience. Their responses informed interviews and focus groups to identify and build on what works well within organisations, stimulates innovation and creates a future 'destiny', rather than examining only the perceived problems in the system. ${ }^{13-16}$

\section{Patient and public involvement}

The research question was informed by patients' experiences through their feedback to PHC clinicians that many patients could not find a FP who would follow their care in the community as their palliative care needs increased. Patients with palliative care needs were being told by their FPs that they would not be able to continue their care because of lack of comfort with palliative care, or lack of willingness or ability to provide home visits as patients became more house-bound.

Patients were involved in the study as participants in our patient and family focus groups through recruitment by the Alberta Health Services Patient and Family Advisory Committee, but were not involved in the design of the study. The participants were provided with a summary of the study's findings for 'member checking' to ensure our framework resonated with the patients and family members.

Patients and caregivers were not included in the design, conduct or reporting of this study as designed in 2017.

\section{Study setting and sample}

FPs were recruited from Calgary area Primary Care Networks (PCN) through advertising in PCN newsletters and used PCN email distribution lists to find interested FPs. PCNs are geographically located networks of FPs and interdisciplinary primary care clinicians working in teambased environments to improve primary care access and care for patients. ${ }^{17}$ Contacting the different PCNs allowed for purposeful ${ }^{18}$ sampling of FPs from both urban and rural regions within the Calgary health zone. Snowball sampling was also used by providing each participant with contact information to pass along to colleagues who may be interested in participating in the study. Theoretical sampling ${ }^{19}$ was used to guide data collection for further insights to support the team's evolving understanding of emerging concepts by identifying more practising FPs who could confirm or disconfirm the evolving analysis. Informed consent was obtained from each participant at the beginning of the interview. 
Purposeful sampling was also used in recruiting PHC clinicians to better understand their perspectives in working with FPs. Two PHC teams from different quadrants of the city, each with its own unique patient demographics, volunteered to participate. Patients and caregivers of patients with palliative care needs were recruited through the Alberta Health Services' Patient and Family Advisory Group, a group of public volunteers with a variety of healthcare patient experiences, ${ }^{20}$ who provided input on the patient and caregiver experience with receiving palliative care.

\section{Data collection}

The FPs participated in individual semi-structured interviews with a research assistant conducted either in person, by telephone, or through Skype for Business depending on the participant's preference. A semi-structured interview guide was developed using AI principles to assess and explore the current clinical landscape regarding family medicine and the provision of CPPC. Demographic information including gender, years of practice, additional palliative care training and country of medical school was collected (table 1).

Distinct focus groups were used to discuss the perspectives and experiences of the patients, bereaved informal caregivers and PHC teams. Basic demographics such as age range, credentials, years of clinical practice and medical condition were collected for these two groups (table 1). A semi-structured focus group guide incorporating AI principles asked participants for their reactions and thoughts on the 'Possibility Statements' ${ }^{\text {'1 }}$ (box 1) that were generated after analysis of the FP interviews in the first phase of the project (see the data analysis section for more details). Each of these specific groups had more than one focus group scheduled to accommodate the availability of consenting participants and were conducted by the principal author.

Field notes capturing key observations from the interviews and focus groups were used to inform future interviews and focus groups as part of an iterative process.

Table 1 Demographics collected for family physicians, patients and caregivers, and palliative home care team members

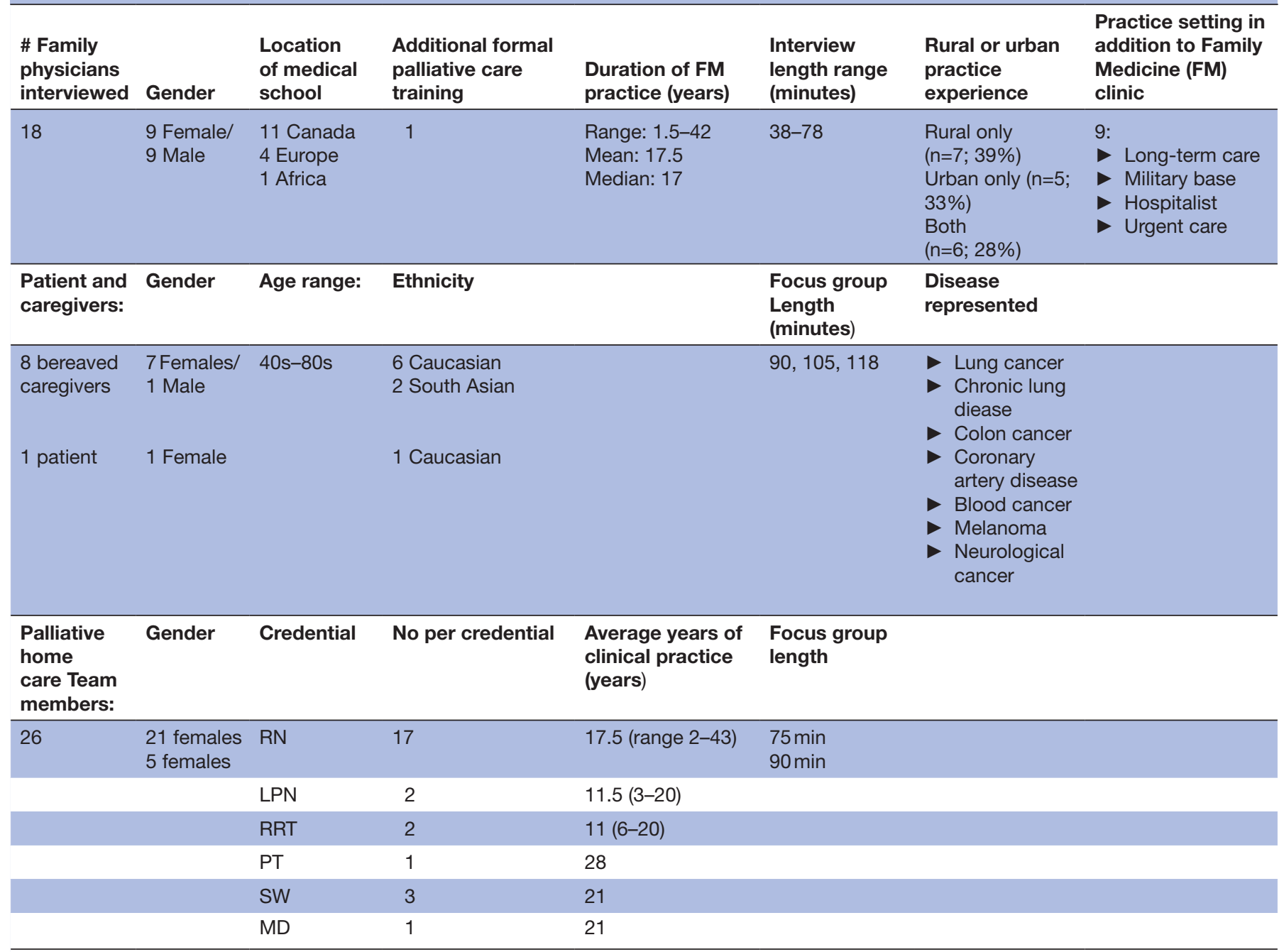

LPN, Licensed Practical Nurse; MD, Medical Doctor; PT, Physiotherapist; RN, Registered nurse; RRT, Registered Respiratory Therapist; SW, Social Worker. 
Box 1 Possibility statements from family physician appreciative inquiry interviews

Possibility statement

1. Everyone (all clinicians, healthcare professionals, patients, caregivers, family) will value the longitudinal family physician-patient relationships with the patient as the focus.

2. All colleagues will consider the family physician as part of the patient's team.

3. There will be flexibility and nimbleness in system to respond to individual patient/family needs.

4. Each family physician will have a high-functioning team (within family medicine) to support the patient.

5. There will be enhanced multidirectional communication between all clinicians and care providers, leveraging technology as appropriate. The onus of the communication between clinicians must not fall on the patients and their caregivers.

6. Family physicians will champion the 'Palliative Approach to Care' for their patients.

7. There will be ongoing, affordable and easily accessible educational opportunities for all healthcare providers who support patients with palliative care needs.

8. Remuneration for family physicians will be improved to better support the needed time (including travel time) and flexibility required to support patients in the community with palliative care needs, that is, home visits, phone calls, team conferences virtually.

\section{DATA ANALYSIS}

\section{FP interviews}

All interviews and focus groups were audiorecorded and transcribed into smart verbatim by an approved and confidential transcription service. Transcripts were checked for accuracy. Qualitative thematic content analysis of the transcripts was conducted through line-by-line analysis for themes as they emerged. The three authors and a research assistant (SD) independently reviewed, analysed the transcripts first and met to discuss overall impressions regarding thematic content and to identify areas for further exploration in future stages of the data collection. Consensus was reached on the identified primary themes for the FP perspectives. All three authors are experienced researchers and clinicians in palliative care, while the lead author also practices comprehensive family medicine. The research assistant did not have any clinical background. These varied perspectives facilitated grounding of the analysis in the real-life clinical context. The emerging themes were then used to develop a framework to which further analyses were compared with ensure that theme saturation was achieved through subsequent interviews ${ }^{22}$ in an iterative manner. These themes were then used to generate 'Possibility Statements' ${ }^{, 15} 21$ according to AI methodology (box 1), which describe the ideal future destination in affirmative language and present tense without stipulating how to achieve this future destination.

\section{Focus groups with PHC team members and patients/ caregivers}

The transcripts from the different focus groups were analysed by thematic content analysis for themes as they emerged inductively by the principal author and a research assistant (CP). The focus group transcripts were also analysed deductively ${ }^{23}$ against the 'Possibility Statements' that were derived from the FPs to test the future destination from other perspectives.

\section{Development of conceptual framework to describe the 'destiny' state}

Consensus was reached by the three authors, through discussion of the themes as part of the iterative analysis, allowing for a deeper understanding of the different themes that had emerged. An audit trail kept throughout the project allowed for constant comparison of the data and memorandums were used to delve into the interpretation of the data, and of emerging relationships between themes and concepts. As these memos were sorted and grouped through constant comparison, relationships emerged that created categories that led to the development of the conceptual framework ${ }^{24}$ for achieving the "destiny" state.

\section{Rigour of study methods}

In keeping with accepted criteria for rigour in qualitative research (credibility, dependability, confirmability and transferability), ${ }^{25}$ our research team detailed the approach to analysis clearly and ensured we had appropriate expertise within our research team. The semi-structured interview guides were pilot-tested with similar test subjects who did not participate in the actual study. Purposeful sampling achieved an excellent variety of perspectives to ensure a wellrounded exploration in the interviews and focus groups.

Analysis was performed initially by the principal investigator (AT) and a research assistant (SD). Intercoder reliability was ensured by AT and SD meeting at regular interviews and individually coding transcripts. The other two authors were also involved in individually coding the transcripts and regular meetings with the principal author. These iterative processes ensured coding accuracy, deepened the emerging understanding of the analysis and achieved consensus through discussions of differing views. Saturation was surpassed for all three groups that participated in interviews and focus groups. Memos and an audit trail were kept throughout the study from inception through to analysis to developmental of the conceptual framework. The analysis of the three groups of participants was completed separately and then triangulated with each other through constant comparison to create the thematic framework that laid the foundation for the conceptual framework.

The conceptual framework was triangulated with FPs, caregivers, palliative care providers and other stakeholders who were not participants in the study to ensure that it resonated with their perspectives as an additional check for validity.

\section{RESULTS}

\section{Demographics}

The demographics collected for the three groups of participants for this study are detailed in table 1 . 
Twelve of the FPs self-identified as actively providing palliative care as part of their practice while six physicians did not include palliative care as a substantial portion of their practice. These six physicians did agree philosophically that primary palliative care was within the scope of a FP to some extent but lacked practical experience in implementing this as part of their practice.

\section{Possibility statements through AI FP interviews}

The AI approach to the FP interviews and analysis uncovered eight key areas (table 1). These eight themes created the possibility statements that described the FP participants' collective vision for a future 'destiny' state and online supplemental appendix 1 has detailed descriptions of each statement.

I think the holistic approach of family medicine, [is] of treating the patient, treating the family, treating the disease symptoms, and also ...the whole being of the patient as well. So, the palliative process as well.
And so they [family physicians] should, I think, have an important role in that.

\section{Results from the focus groups with patients and bereaved caregivers and PHC team}

The themes derived from the AI focus groups were triangulated with each other and are organised below in this table. Exemplar quotes to support these themes are found in the expanded table in online supplemental appendix 2.

\section{Conceptual framework}

Based on iterative reorganising ${ }^{24}$ of the themes (table 2), above, a conceptual framework emerged that brought all different perspectives together to describe how to achieve this 'destiny' state. This conceptual framework is shown in a visual schematic below with the symbols in the legend and describes how clinicians, the health system and society can more optimally help improve the

Table 2 Themes from focus groups held with FP, patients and caregivers, and palliative home care (PHC) teams

\begin{tabular}{|c|c|c|c|}
\hline Category & $\begin{array}{l}\text { Family physicians (FP) } \\
\text { themes }\end{array}$ & $\begin{array}{l}\text { Patient and caregivers } \\
\text { themes }\end{array}$ & $\begin{array}{l}\text { PHC } \\
\text { themes }\end{array}$ \\
\hline $\begin{array}{l}\text { 1) Patient's } \\
\text { relationship with } \\
\text { FP needs to be } \\
\text { fostered and } \\
\text { valued }\end{array}$ & $\begin{array}{l}\text { Value of FP-patient } \\
\text { relationships for the } \\
\text { patient } \\
\text { Colleagues to consider } \\
\text { FPs part of the patient's } \\
\text { team }\end{array}$ & $\begin{array}{l}\text { Encourage ongoing relationship with FP } \\
\text { throughout illness so FPs have been in } \\
\text { the loop } \\
\text { FPs can help patients/caregivers navigate } \\
\text { system and illness course }\end{array}$ & $\begin{array}{l}\text { Encourage ongoing } \\
\text { relationship with FP } \\
\text { throughout illness so FPs } \\
\text { have been in the loop }\end{array}$ \\
\hline $\begin{array}{l}\text { 4) Understanding } \\
\text { palliative approach } \\
\text { to care }\end{array}$ & $\begin{array}{l}\text { FPs to champion palliative } \\
\text { approach to care }\end{array}$ & $\begin{array}{l}\text { Early discussion of what palliative } \\
\text { care really is so can accept help and } \\
\text { understand this in making treatment } \\
\text { decisions (ACP and goals of care) }\end{array}$ & $\begin{array}{l}\text { Health care system and } \\
\text { public need to better } \\
\text { understand palliative care }\end{array}$ \\
\hline $\begin{array}{l}\text { 5) Healthcare } \\
\text { system needs }\end{array}$ & $\begin{array}{l}\text { Need flexibility and } \\
\text { nimbleness in system } \\
\text { Remuneration for FPs } \\
\text { needs to improve (travel, } \\
\text { telecommunication visits) }\end{array}$ & $\begin{array}{l}\text { System should support patients in the } \\
\text { community, not rely on informal caregivers } \\
\text { More resources for different levels of } \\
\text { home care needed throughout trajectory } \\
\text { FPs need to be able to have longer appts } \\
\text { Use telecommunication technology to be } \\
\text { able to be in easier contact with FPs for } \\
\text { questions, not necessarily home visits. }\end{array}$ & $\begin{array}{l}\text { Better transitions and } \\
\text { handovers between care } \\
\text { sectors } \\
\text { More resources for } \\
\text { different levels of home } \\
\text { care needed throughout } \\
\text { trajectory }\end{array}$ \\
\hline
\end{tabular}

ACP, Advance Care Planning; FP, Family Physician; PHC, Palliative Home Care. 


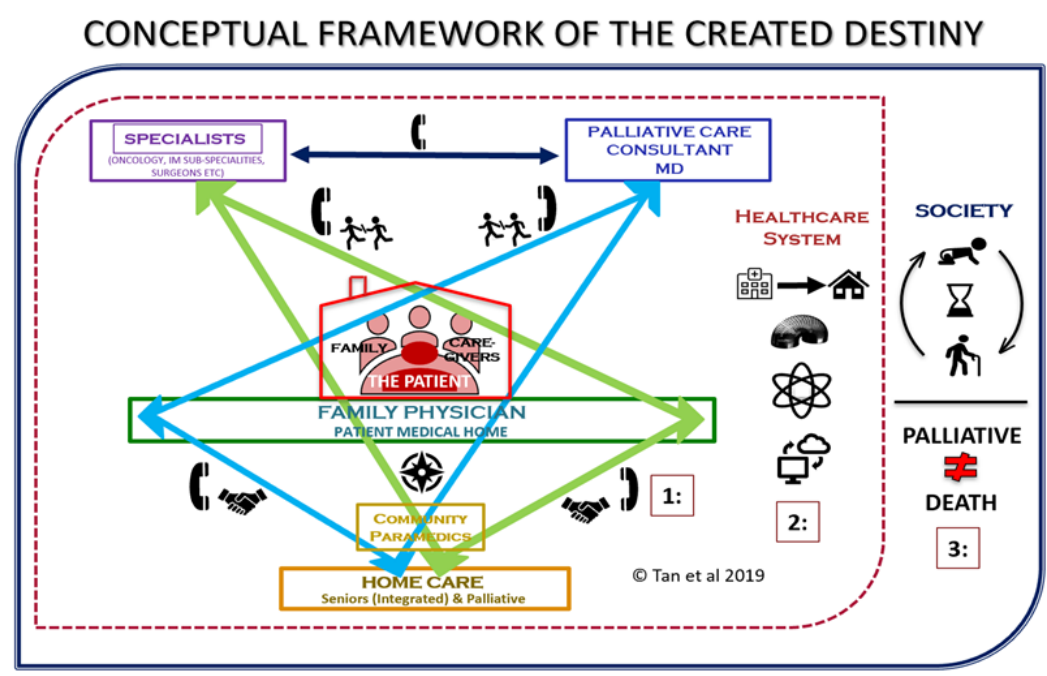

1:, 2:, 3: See text for descriptions of these concepts

Symbols Legend:

\begin{tabular}{|c|l|c|l|}
\hline $\mathbf{1}$ & Direct \& Active Communication & Flexiblilty \\
\hline & Explicit Warm Handovers & 8 & Break down silos \\
\hline & Invest in team relationships & & $\begin{array}{l}\text { Telecommunication investment (real- } \\
\text { time/two-way) }\end{array}$ \\
\hline
\end{tabular}

Figure 1 Conceptual Framework of the panoramic view on how to achieve the 'destiny' state.

patient's and family's journey when a person has palliative care needs. The following will describe the details that the visual schematic represents.

\section{Overall conceptual framework description}

The conceptual framework (figure 1) places the patient with their family at the centre, surrounded by caregivers supporting the patient in the community. Alongside the patient and caregivers is the FP within the $\mathrm{PMH}$ as the longitudinal support that is the foundation of the Canadian healthcare system. The patient and caregivers' journey are directly intertwined as the people whom the clinicians serve. The patient's, family and caregivers collective journey is directly influenced by two inter-related relationship triads. We use the concept of the 'Loran', ${ }^{26}$ short for LOng-Range Aid to Navigation, a system of navigation that uses signals between three points to determine one's course for a journey, in this case the journey of the patient, family and caregivers. These relationship triads exist and interact with each other within the healthcare system and the larger society in which we all live. The key parts of the Loran conceptual framework are: (1) Two interrelationship triads, (2) Triads exist within health system and (3) Triads and health system exist within a larger society.

The two interrelationship triads based on the 'Loran' concept The first relationship triad (figure 2) is between the patient's FP, home care providers and specialist consultants (eg, oncologists, surgeons). The second relationship triad (figure 3 ) is between the patient's FP, home care providers and palliative care consultants, including advanced practice nurses, nurse practitioners and consultant physicians.

Our analysis found that these relationship triads are positively impacted by the upstream enablers that each clinician would have enacted prior to working within the triad. These upstream enablers optimised the possibility of an effective, collaborative working relationship between these clinicians to improve the patient's journey together. Once working together, the framework also illustrates the ongoing facilitators that emerged as essential to enhance the collaboration among the clinicians working with the patient and caregivers (figure 4).

Table 3 details the upstream enablers and the facilitators that would enhance collaboration among the clinicians, for the benefit of the patient and caregivers.

\section{The Loran triads exist within a healthcare system (dotted red} line)

The conceptual framework is grounded by these two Loran triads that influence the patient and caregiver illness journey. However, even if these Loran triads are well established with all clinicians having engaged in the upstream enablers listed in table 3 , and working collaboratively together, it must be acknowledged that these 


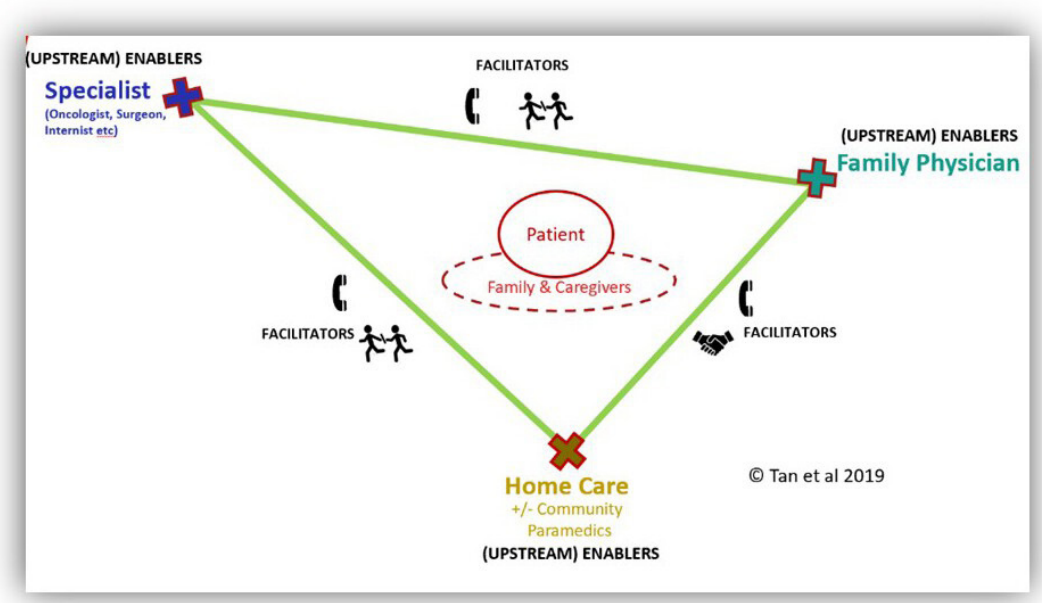

Figure 2 First relationship 'Loran' triad: family physician-home care-specialist consultant(s).

cannot exist in isolation. These relationships must exist in the healthcare system, which also requires improvements to better support patients and caregivers in their community-based palliative care journey (figure 5).

The key components that were identified as required within the healthcare system were: (1) resources focused more on community than acute care facilities, (2) system flexibility to respond to individual patient needs, (3) elimination of silos between clinicians, disciplines and organisations to improve collaboration and efficiency and decrease redundancies and confusion, (4) use of secure teleconferencing modalities to improve access and support for patients regardless of location and (5) a universal electronic record system to improve communication among all clinicians, care providers and patients.

In turn, the healthcare system exists within the larger society that it serves (figure 6).

Analysis identified that patients, caregivers and clinicians agreed that more public education is required to help everyone inside and outside the healthcare system understand that Palliative Care does not mean end of life or imminent death. This would allow involvement of palliative care supports earlier in the disease trajectory. Additionally, public discourse will normalise conversations about mortality and decrease stigma and fears about death, dying and appropriate treatment decisions in accordance with patients' goals.

\section{DISCUSSION}

This study explores and describes behaviours and health system components that are required to improve the coordinated and collaborative care for community-based patients with palliative care needs and their family and unpaid caregivers. We interviewed FPs who practice in a large Canadian city and surrounding rural area. Using AI methodology, we identified 'possibility statements' that described a future 'destiny' state. These 'possibility statements' were presented to bereaved caregivers and patient focus groups, as well as two PHC teams, to determine their reactions and perspectives to then create a panoramic view of the 'destiny' state. Based on our analysis, we

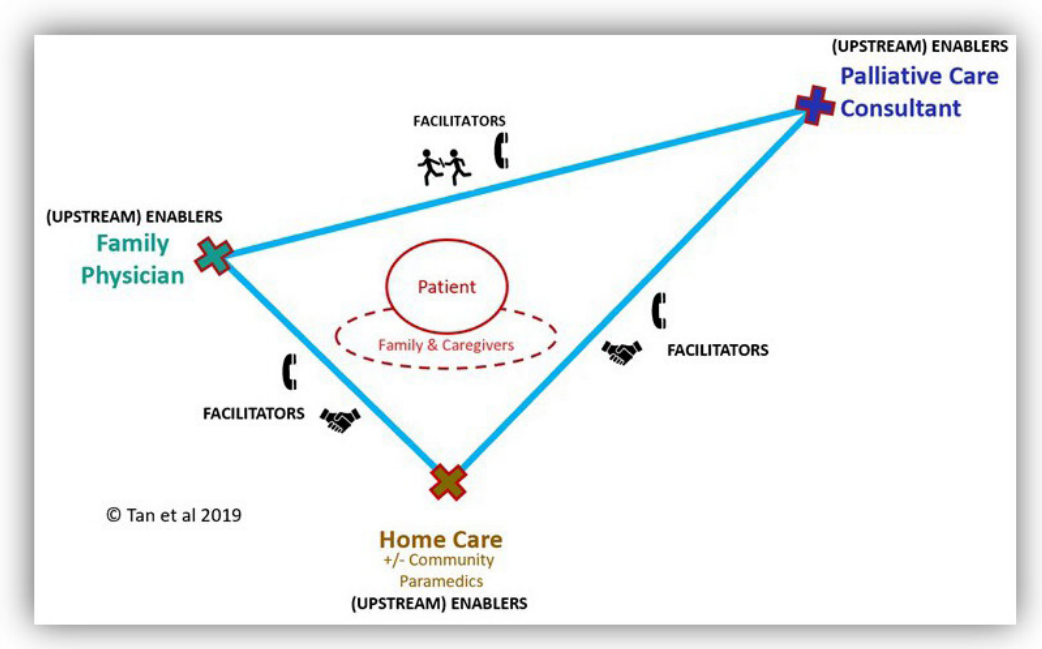

Figure 3 Second relationship ‘Loran' triad: family physician-home care-palliative care consultant(s). 


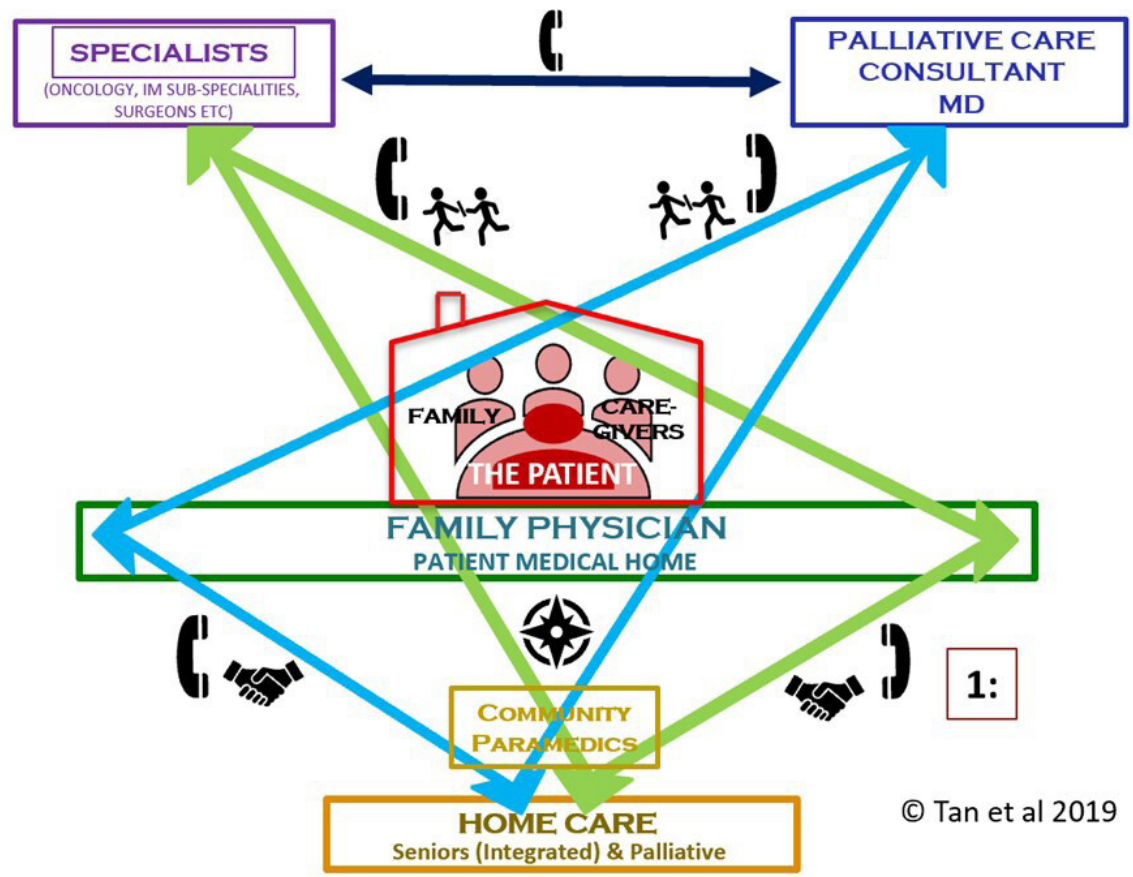

Figure 4 Both 'Loran' triads overlapping with upstream enablers and facilitators incorporated.

developed a conceptual framework that describes how to achieve this "destiny" state with the patient and family journey as the central focus. It is anchored by two 'Loran' triads that describe the effective collaboration required between the four different groups of clinicians (FPs, specialists, palliative care consultants, home care), who support the patient and family.

This conceptual framework is a significant development in the primary palliative care literature as its key contribution identifies the explicit ways that the healthcare team, healthcare system and societal attitudes can be optimised to improve the care of patients with palliative care needs. While the roles and responsibilities of different healthcare providers have been explored in the provision of palliative care,${ }^{59}$ this is the first comprehensive framework that pulls all of these perspectives and roles together.

Our study identified several other key findings that other studies have also reported. Effective teamwork among clinicians and care providers of all disciplines was universally recognised as the most important component. ${ }^{27-29}$ The different perspectives elicited multiple ways to improve and optimise the patient and caregiver journey through the palliative care illness trajectory. With the patient as the central focus of the team, ${ }^{27-29}$ all care is guided by the patient's preferences, values and needs. ${ }^{30}$

Another key enabler identified was strong, continuous relationships between FPs and patients, focusing on the 'whole person' ${ }^{\text {'31 }}$ using the $\mathrm{PMH}^{30}$ model throughout their illness, enhances care and avoids gaps in treatment. Continuous FP and PMH involvement can also help family members and loved ones access bereavement and grief support, reducing the existing unmet need where care ends once a patient is deceased. ${ }^{32} \mathrm{PMHs}$ have demonstrated success in improving access to the health system, enhancing quality of care, improving coordination of care, reducing reliance on acute care facilities and encouraging a team-based care model ${ }^{33}$ FPs within these PMHs can use the multidisciplinary team-based care model, reducing reliance on acute care facilities by patients ${ }^{33-37}$ and encouraging a team-based care model.

Increased investment in community-based home care teams that are skilled in both the palliative approach to care and primary palliative care skills is essential to support patients in the community. ${ }^{38}$ More home care resources for patients with palliative care needs and improved collaboration with FPs lessens the burden for families. Studies have found that patients with palliative care needs desired regular home visits by their $\mathrm{FP}^{39}{ }^{39}$ yet our study found that patients and caregivers want ongoing availability of their FP on an as-needed basis by phone rather than regular or frequent home visits. A recent study determined that patients in rural communities found that the use of web-based teleconferencing with a physician consultant was a convenient and acceptable way to address their concerns and the physicians noted improved patient access in a time-efficient manner. ${ }^{40}$ The home care team member played an essential bridge that supplied the teleconference equipment to the patient's home, and also acted as the eyes and ears for the physician. The use of technology shows promise in encouraging more FPs to maintain regular contact with patients with palliative care needs in the community. While this study was conducted prior to the SARS-COV-2 pandemic, the sudden necessity to employ virtual care at the height of the Canadian public health lockdowns in March 2020 demonstrated the importance of the use of technology to support patient care. ${ }^{41} 42$ The lessons learnt during the 
Table 3 The upstream enablers enhancing collaboration among clinicians for care of patients and caregivers

\begin{tabular}{|c|c|c|c|c|}
\hline & Palliative home care & Family physician (FP) & Specialist consultant & Palliative care consultant \\
\hline $\begin{array}{l}\text { Upstream } \\
\text { Enablers }\end{array}$ & $\begin{array}{l}\text { Can provide the } \\
\text { 'Palliative Approach to } \\
\text { Care' } \\
\text { Earlier access during } \\
\text { disease- modifying } \\
\text { treatments } \\
\text { Help patient navigate } \\
\text { the system } \\
\text { More resources for } \\
\text { respite and bedside } \\
\text { nursing care } \\
\text { Less silos for } \\
\text { Continuing Care/Long- } \\
\text { term Care }\end{array}$ & $\begin{array}{l}\text { Advance care planning } \\
\text { with patient } \\
\text { re: illness trajectory } \\
\text { Reach out to patient and } \\
\text { family throughout illness } \\
\text { Focus on relationship and } \\
\text { help patient navigate the } \\
\text { system } \\
\text { Champion the 'Palliative } \\
\text { Approach to Care' } \\
\text { (patient-centred care) } \\
\text { Utilise family medicine } \\
\text { interdisciplinary team } \\
\text { to provide holistic } \\
\text { support for patients and } \\
\text { caregivers }\end{array}$ & $\begin{array}{l}\text { Advance care } \\
\text { planning with } \\
\text { patient } \\
\text { Check on } \\
\text { understanding of } \\
\text { illness trajectory } \\
\text { and treatment } \\
\text { goals } \\
\text { Adopt Palliative } \\
\text { Approach to Care } \\
\text { Consistent } \\
\text { messaging re: } \\
\text { FP involvement } \\
\text { throughout illness } \\
\text { that is: don't } \\
\text { undermine the FP- } \\
\text { patient relationship }\end{array}$ & $\begin{array}{l}\text {-Consistent messaging re: } \\
\text { FP involvement throughout } \\
\text { illness }\end{array}$ \\
\hline \multirow[t]{2}{*}{$\begin{array}{l}\text { Facilitators for } \\
\text { collaborative } \\
\text { relationships }\end{array}$} & $\begin{array}{l}\text { Family physician and } \\
\text { home care }\end{array}$ & $\begin{array}{l}\text { Family physician and } \\
\text { specialist or palliative care } \\
\text { consultant }\end{array}$ & & \\
\hline & $\begin{array}{l}\text { Mutual trust and } \\
\text { respect } \\
\text { Role clarity and rules } \\
\text { of engagement } \\
\text { Regular, pre- } \\
\text { emptive two-way } \\
\text { communication } \\
\text { Plan for acute/rapid } \\
\text { changes and needs } \\
\text { Invest in and develop } \\
\text { a collaborative team } \\
\text { relationship }\end{array}$ & $\begin{array}{l}\text { Mutual trust and respect } \\
\text { Role clarity and rules of } \\
\text { engagement with explicit } \\
\text { handovers } \\
\text { Direct two-way } \\
\text { communication }\end{array}$ & & \\
\hline
\end{tabular}

pandemic will expedite the sustained healthcare system changes needed to better support house-bound patients with palliative care needs beyond the pandemic. ${ }^{43}$ Care must be taken to ensure virtual care improves continuity between care providers and the patient with palliative care needs, rather than allowing for convenience with episodic care to dominate over longitudinal relationships with a FP.

The longitudinal relationship between a patient and trusted FP must be encouraged, valued and fostered by everyone in in the care team. Strong collaboration within interdisciplinary care teams builds respect, trust and competence among FPs, the home care team and specialists. ${ }^{28} 44$ Our study describes safe and open communication among team members in a supportive team environment. A clear understanding of team member roles, responsibilities and processes, and providing space for flexibility resonated with all stakeholders who participated in our study. Unfortunately, the bereaved caregivers and patients in our study commented that they often received contradictory messages from specialists and palliative care consultants that undermined their relationship with and trust in their FP. An Ontario study found that patients with palliative care needs who had FP visits less than 6 months from death were facilitated by their satisfaction in their FP's care, which included the desire for psychosocial support by their FP and caregiver support. ${ }^{45}$ Affirmation of the FP's role by all care providers and improved role clarity will improve trust and strengthen relationships between clinicians. ${ }^{45}$

FPs pointed out that they desire to provide palliative care to their patients, but because these patients make up a small subset of their overall generalist practice, they need the support of the team. This includes easier access to their specialist colleagues for help or advice for their patients. Anvik et $a l^{31}$ also found that patient care improves when generalists and specialists reinforce each other. When specialists and FPs can actively work together and share the care of their mutual patient, there is less risk of FPs being left to 'hold the bag', 27 and a collaborative "sharing of the load" 27 occurs that benefits the patient. Coaching FPs to manage more routine palliative 


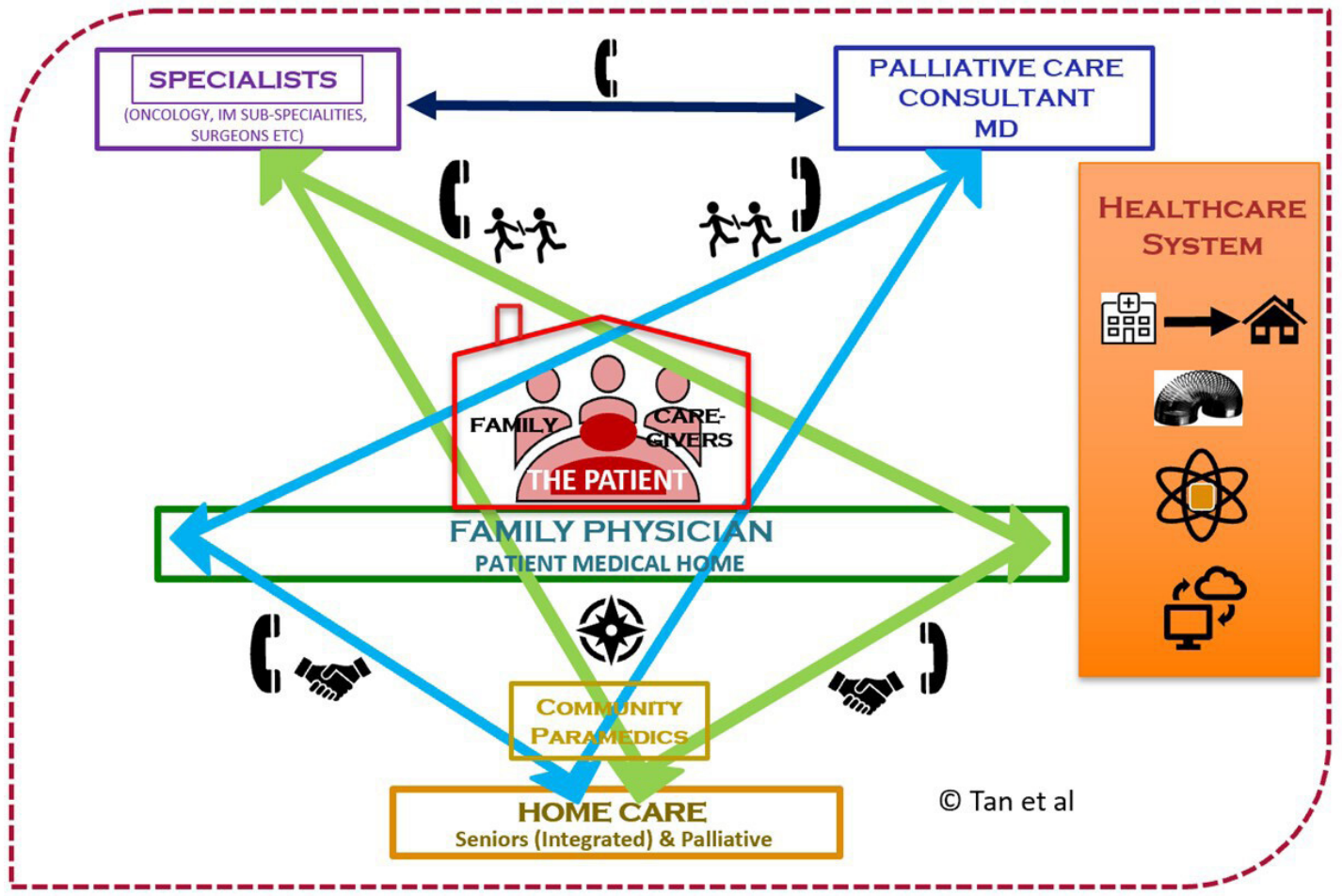

Figure 5 The Loran triads exist within a healthcare system (dotted red line).

care situations in a team-based approach will help to meet patients' needs regarding continuity, while knowing that the specialty palliative care team can be increasingly involved in an integrated manner if the situation becomes more complex or beyond the scope of primary palliative care.

This study reiterates the concern that the medical community and society at large do not have a good understanding of what palliative care can offer patients and their family members. Palliative care does not mean that the patient is imminently dying. As clinicians improve their skills and embrace the palliative approach ${ }^{46-48}$ to care, patients and families will be better supported in their serious illness journey and will be less threatened by the palliative approach to care. Open conversations about a patient's illness trajectory and prognosis will lead

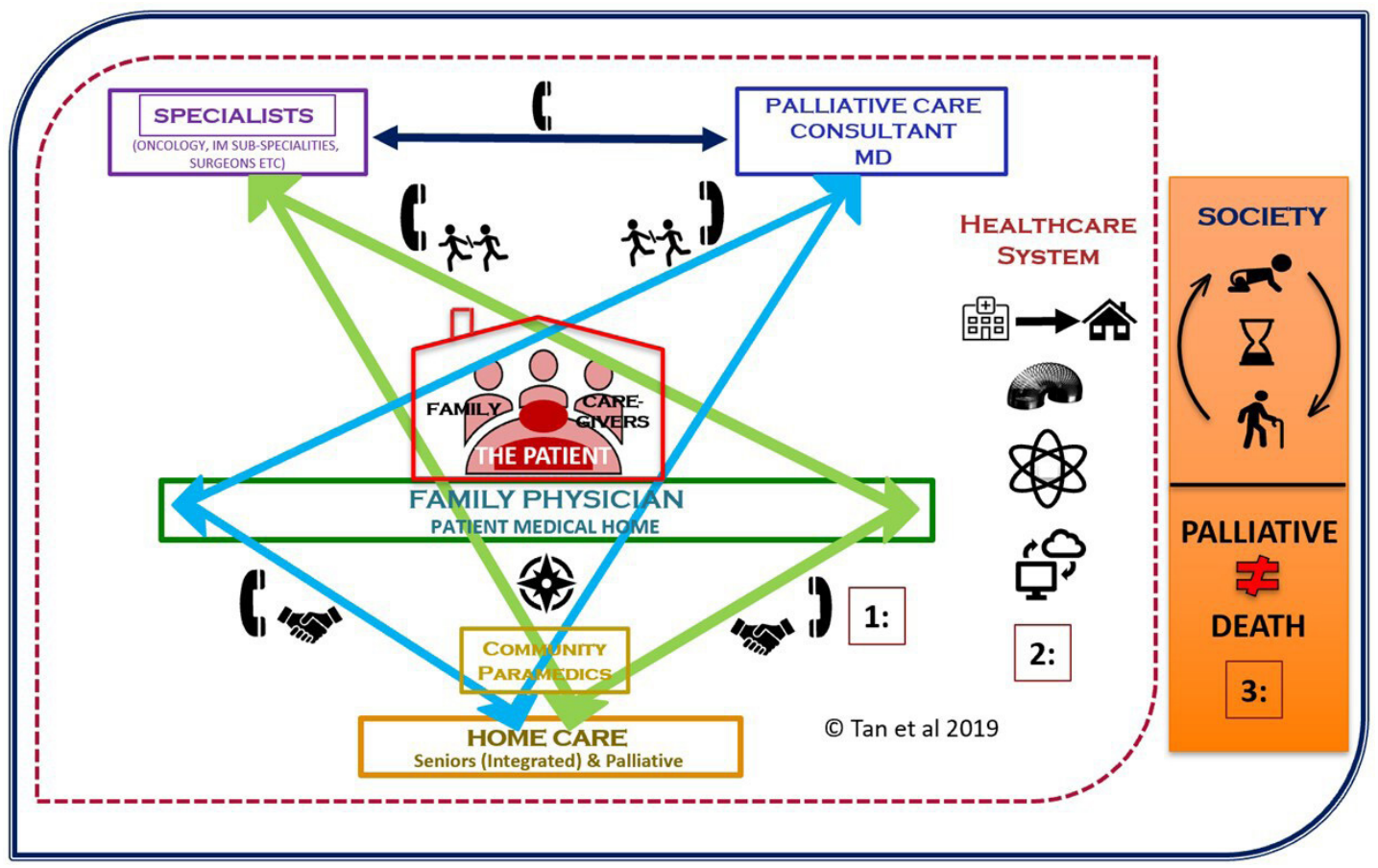

Figure 6 The healthcare system and the Loran triads exist within the larger Society (outer blue line). ${ }^{3}$ 
to earlier and more effective advance care planning for patients. ${ }^{49}$ Collaboration and improved communication between specialists and FPs will result in less conflict in messaging and will help to ensure that caregivers are better ${ }^{50}$ prepared for substitute decision-making. Increasing public discourse ${ }^{51}$ about death and dying may empower clinicians to have important conversations with patients and might limit the use of ineffective or unwanted medical treatments. Compassionate and coordinated care in the PMH will reduce fear and improve decision making in the midst of life-limiting illness.

\section{Strengths and limitations of study}

This study's strength lies in the innovative solutions-based AI approach to determine how best to support patients and their families in the community with palliative care needs. Additionally, exploring the perspectives of FPs, PHC providers and their patients and unpaid caregivers and triangulating their insights allowed for the development of a conceptual framework from important yet varied stakeholder perspectives.

As with any qualitative study, the results of this study may not be generalisable to other regions. The recruitment of patients and caregivers was limited in number and in diversity of demographics as we were dependent on volunteers through an arms-length organisation for ethical reasons. However, the content of the focus groups involving patients and caregivers did surpass saturation in analysis and we were satisfied with the richness of the data collected for this perspective.

\section{FUTURE WORK}

Future work would include implementation of specific practical aspects of the conceptual framework that this study created that integrates with emerging best practices for improving purposeful team collaboration. ${ }^{5}$ Studying the work of an initial small group of early adopters who learn and implement key parts of this framework to enable effective team strategies, strengthen the homecare system and promote societal changes required to support patients with palliative care needs could inform others in implementation. More work is required to explore FPs' definitions, attitudes and comfort with integrating different components of palliative care. Identifying FPs who are 'palliphilic' (vs 'palliphobic' ${ }^{52}$ ) could allow for these early adopters to implement the practical aspects in our conceptual framework to promote sustainable system change.

\section{CONCLUSION}

A strong, effective collaborative relationship between the FP with all other care providers is critical to support patients with palliative care needs and their caregivers in the community, as is building on the trusting FP-patient longitudinal relationship. Key areas were identified for how all members of the patient's team can work together effectively to improve the patient and caregiver palliative care journey.

Twitter Amy Tan @AmyTanMD and Aynharan Sinnarajah @DrASinnarajah

Acknowledgements The authors would like to thank Dr Jessica Simon and Dr Patricia Biondo for their help in the background work for this project and in its connection to the PaCES-Palliative Care, Early and Systematic research program at the University of Calgary. We would like to Ms. Sharlette Dunn, Ms. Carley Paterson and Ms. Nicole Frenette for their help in the data collection and analysis and formatting of the manuscript as research assistants during different stages of the project. We are grateful for the wisdom and support of the Alberta Health Services Patient and Family Advisory Council for helping to recruit patient and family participants and communicating our research findings back to them.

Contributors AT, RS and AS conceptualised the study. AT designed the study with feedback from RS and AS. AT led the data collection and supervised the research assistants (SD, CP, NF). All authors reviewed the transcripts and contributed to the analysis. AT led the manuscript writing with contributions from RS and AS. All authors reviewed the transcript. AT acts as the guarantor.

Funding This work was supported by a Janus Research Grant from the Foundation for Advancing Family Medicine of the College of Family Physicians of Canada and a Grant from Alberta Health.

Competing interests None declared.

Patient consent for publication Not applicable.

Ethics approval This study received ethical approval (REB17-1230) from the Conjoint Health Research Ethics Board (CHREB) at the University of Calgary, Canada.

Provenance and peer review Not commissioned; externally peer reviewed.

Data availability statement Data are available on reasonable request. The deidentified data, transcripts, memos and field notes are securely stored on a secure hard drive and are available on reasonable request.

Supplemental material This content has been supplied by the author(s). It has not been vetted by BMJ Publishing Group Limited (BMJ) and may not have been peer-reviewed. Any opinions or recommendations discussed are solely those of the author(s) and are not endorsed by BMJ. BMJ disclaims all liability and responsibility arising from any reliance placed on the content. Where the content includes any translated material, BMJ does not warrant the accuracy and reliability of the translations (including but not limited to local regulations, clinical guidelines, terminology, drug names and drug dosages), and is not responsible for any error and/or omissions arising from translation and adaptation or otherwise.

Open access This is an open access article distributed in accordance with the Creative Commons Attribution Non Commercial (CC BY-NC 4.0) license, which permits others to distribute, remix, adapt, build upon this work non-commercially, and license their derivative works on different terms, provided the original work is properly cited, appropriate credit is given, any changes made indicated, and the use is non-commercial. See: http://creativecommons.org/licenses/by-nc/4.0/.

ORCID iDs

Amy Tan http://orcid.org/0000-0003-2063-4919

Aynharan Sinnarajah http://orcid.org/0000-0002-7967-159X

\section{REFERENCES}

1 Canadian Institute for Health Information. Access to palliative care in Canada, 2018. Available: https://www.cihi.ca/sites/default/files/ document/access-palliative-care-2018-en-web.pdf [Accessed $23 \mathrm{Apr}$ 2018].

2 Bekelman JE, Halpern SD, Blankart CR, et al. Comparison of site of death, health care utilization, and hospital expenditures for patients dying with cancer in 7 developed countries. JAMA 2016;315:272-83.

3 CBC News. End of life care in Canada more hospital-centric than in US, Europe, 2016. Available: http://www.cbc.ca/news/health/end-oflife-palliative-hospice-1.3410064 [Accessed 23 Apr 2018].

4 The College of Family Physicians of Canada. Family medicine professional profile, 2018. Available: https://portal.cfpc.ca/ resourcesdocs/uploadedFiles/About_Us/FM-Professional-Profile.pdf [Accessed 23 Apr 2018].

5 Koper I, Pasman HRW, Schweitzer BPM, et al. Variation in the implementation of PaTz: a method to improve palliative care in 
general practice - a prospective observational study. BMC Palliat Care 2020;19:10.

6 Mitchell S, Tan A, Moine S, et al. Primary palliative care needs urgent attention. BMJ 2019;365:11827.

7 Mitchell GK. The role of general practice in cancer care. Aust Fam Physician 2008;37:698-72.

8 World Health Organization. WHO definition of palliative care. Available: https://www.who.int/cancer/palliative/definition/en/ [Accessed 23 Apr 2018].

9 Hui D, Bruera E. Models of integration of oncology and palliative care. Ann Palliat Med 2015;4:89-98.

10 Temel JS, Greer JA, Muzikansky A, et al. Early palliative care for patients with metastatic non-small-cell lung cancer. N Engl J Med 2010;363:733-42.

11 Patient's Medical Home. Vision- What We're About, 2020. Available: https://patientsmedicalhome.ca/vision/ [Accessed 23 Apr 2018].

12 O'Brien BC, Harris IB, Beckman TJ, et al. Standards for reporting qualitative research: a synthesis of recommendations. Acad Med 2014;89:1245-51.

13 Thin Book Publishing. Appreciative inquiry, 2013. Available: https:// www.thinbook.com/appreciative-inquiry [Accessed 23 Apr 2018].

14 Cooperrider DL, Whitney D. Appreciative inquiry: a positive revolution in change. San Francisco, CA: Berrett-Koehler Publishers, Inc, 2005.

15 Whitney D, Trosten-Bloom A. The power of appreciative inquiry: a practical guide to positive change. San Francisco, CA: BerrettKoehler Publishers, Inc, 2003.

16 Al Commons. Introduction to appreciative inquiry. Available: https:// appreciativeinquiry.champlain.edu/learn/appreciative-inquiryintroduction/ [Accessed 23 Apr 2018].

17 Primary Care Network Calgary Foothills. Primary care networks. Available: https://cfpcn.ca/primary-care-network/ [Accessed $23 \mathrm{Apr}$ 2018]

18 Kuzel AJ. Sampling in qualitative inquiry. In: Crabtree BF, Miller WL, eds. Doing qualitative research. Thousand Oaks, CA: Sage Publications, 1999: 33-45.

19 Glaser B. Doing Grounded theory: issues and discussions. 254. Mill Valley, CA: Sociology Press, 1998.

20 Alberta Health Services. Patient experience: Patient \& family advisory group. Available: https://www.albertahealthservices.ca/info/ Page6620.aspx [Accessed 23 Apr 2018].

21 Cooperrider D. Tips for crafting provocative propositions. Al Commons, 2002. Available: https://appreciativeinquiry.champlain. edu/educational-material/tips-for-crafting-provocative-propositions/ [Accessed 23 Apr 2018].

22 Braun V, Clarke V. Using thematic analysis in psychology. Qual Res Psychol 2006;3:77-101.

23 Fereday J, Muir-Cochrane E. Demonstrating rigor using thematic analysis: a hybrid approach of inductive and deductive coding and theme development. Int J Qual Methods 2006;5:80-92.

24 Creswell JW. Research design: qualitative, quantitative, and mixed methods approaches. 260. Los Angeles, CA: Sage Publications, 2009.

25 Forero R, Nahidi S, De Costa J, et al. Application of four-dimension criteria to assess rigour of qualitative research in emergency medicine. BMC Health Serv Res 2018;18:120.

26 Hefley $\mathrm{G}$. The development of Loran-C navigation and timing. Institute for basic standards - national Bureau of standards, 1972. Available: https://archive.org/stream/TheDevelopmentOfLoranCNa vigationAndTiming\#page/n3/mode/2up [Accessed 23 Apr 2018].

27 Manca DP, Breault L, Wishart P. A tale of two cultures: specialists and generalists sharing the load. Can Fam Physician 2011;57:576-84.

28 Nancarrow SA, Booth A, Ariss S, et al. Ten principles of good interdisciplinary team work. Hum Resour Health 2013;11:19.

29 Schottenfeld L, Petersen D, Peikes D. Creating patient-centered team-based primary care: AHRQ PUB. No. 16-0002-EF. agency for healthcare research and quality, us department of health and human services,, 2016. Available: https://pcmh.ahrq.gov/page/creatingpatient-centered-team-based-primary-care [Accessed 23 Apr 2018].

30 Alberta Medical Association. Patient's medical home. Available: https://www.albertadoctors.org/leaders-partners/innovation-inprimary-care/patients-medical-home [Accessed 23 Apr 2018]
31 Anvik T, Holtedahl KA, Mikalsen $\mathrm{H}$. "When patients have cancer, they stop seeing me"--the role of the general practitioner in early followup of patients with cancer--a qualitative study. BMC Fam Pract 2006; 7:19.

32 Tabler J, Utz RL, Ellington L, et al. Missed opportunity: hospice care and the family. J Soc Work End Life Palliat Care 2015;11:224-43.

33 Marshall D, Howell D, Brazil K, et al. Enhancing family physician capacity to deliver quality palliative home care: an end-of-life, shared-care model. Can Fam Physician 2008;54:54.

34 Canadian Cancer Society. Right to care: palliative care for all Canadians, 2016. Available: https://www.cancer.ca/ /media/cancer. $\mathrm{ca} / \mathrm{CW} / \mathrm{get} \% 20$ involved/take\%20action/Palliative-care-report-2016EN.pdf?la=en [Accessed 23 Apr 2018]

35 Almaawiy U, Pond GR, Sussman J, et al. Are family physician visits and continuity of care associated with acute care use at end-of-life? a population-based cohort study of homecare cancer patients. Palliat Med 2014;28:176-83.

36 Meiklejohn JA, Mimery A, Martin JH, et al. The role of the GP in follow-up cancer care: a systematic literature review. J Cancer Surviv 2016;10:990-1011.

37 Aubin M, Vézina L, Verreault $R$, et al. Patient, primary care physician and specialist expectations of primary care physician involvement in cancer care. J Gen Intern Med 2012;27:8-15.

38 Canadian Hospice Palliative Care Association. An integrated palliative approach to care. cost-effectiveness of palliative Care-A literature review, 2012. Available: http://hpcintegration.ca/media/ 24434/TWF-Economics-report-Final.pdf [Accessed 1 Jul 2020].

39 Beernaert K, Van den Block L, Van Thienen K, et al. Family physicians' role in palliative care throughout the care continuum: stakeholder perspectives. Fam Pract 2015;32:cmv072.

40 Read Paul L, Salmon C, Sinnarajah A, et al. Web-based videoconferencing for rural palliative care consultation with elderly patients at home. Support Care Cancer 2019;27:3321-30.

41 Alberta Health Services. COVID-19 scientific advisory group: rapid evidence report, 2020. Available: https://www.albertahealthservices. $\mathrm{ca} /$ assets/info/ppih/if-ppih-covid-19-sag-virtual-vs-in-person-carerapid-review.pdf [Accessed 1 Jul 2020].

42 Schwamm LH, Estrada J, Erskine A, et al. Virtual care: new models of caring for our patients and workforce. Lancet Digit Health 2020;2:e282-5.

43 Moulson N, Bewick D, Selway T, et al. Cardiac rehabilitation during the COVID-19 era: guidance on implementing virtual care. Can J Cardiol 2020;36:1317-21

44 Henneman EA, Lee JL, Cohen Jl. Collaboration: a concept analysis. J Adv Nurs 1995;21:103-9.

45 Moon C, Pope A, Swami N, et al. The role of family physicians in palliative care of patients with advanced cancer. $J$ Pain Symptom Manage 2018;56:E31.

46 Hawley P. Barriers to access to palliative care. Palliat Care 2017; 10:117822421668888.

47 Murray SA, Kendall M, Boyd K, et al. Illness trajectories and palliative care. BMJ 2005;330:1007-11

48 Howard M, Bernard C, Tan A, et al. Advance care planning: let's start Sooner. Can Fam Physician 2015;61:663-5.

49 Bernacki R, Hutchings M, Vick J, et al. Development of the serious illness care program: a randomised controlled trial of a palliative care communication intervention. BMJ Open 2015;5:e009032.

50 Tan A, Manca D. Finding common ground to achieve a "good death": family physicians working with substitute decision-makers of dying patients. A qualitative grounded theory study. BMC Fam Pract 2013;14:14.

51 Penfold-Mounce R. Death: why children should be taught about it in school, 2018. Available: https://theconversation.com/death-whychildren-should-be-taught-about-it-in-school-99541 [Accessed 1 Jul 2020].

52 Hui D, Cerana MA, Park M, et al. Impact of oncologists' attitudes toward end-of-life care on patients' access to palliative care. Oncologist 2016;21:1149-55. 